\title{
The Research on Consumer Behavior of Online Games and Its Influencing Factors
}

\author{
Yasi Zhang ${ }^{1}$, Weilun Huang ${ }^{1, a}$ \\ ${ }^{1}$ School of Finance, Wenzhou Business College, China
}

\begin{abstract}
The purpose of this paper is to explore consumer behavior of online game and its influencing factors by the methods of literature review and questionnaire analysis. The results show that the monthly consumption of online games by respondents exceeds RMB150, and its daily game time is about 3 hours. And the cognitions on the advantages, disadvantages, quality advantages, and quality disadvantages of online game and individual variables of player are all significant influencing factors on consumer behavior of online game. This paper suggests that the government should actively help domestic online games to develop their derivatives and export, and companies should make the differentiated marketing strategies for the consumer groups which divided by their different individual variables.
\end{abstract}

\section{Introduction}

Nowadays (2018), the industry of online game has been an industry in which governments, enterprises and individuals actively participated. The reasons are that the online game industry could let governments promote their economic development and cultural exports, enterprises expand their scope and operating income, and individuals find their satisfaction and accomplishment. Therefore, the scale, scope and players of the online game industry have increased significantly, but there are still few literatures discussing the consumer behavior of online game. Therefore, the purpose of this paper is to study the consumer behavior of online game and its influencing factors. As Zhang (2015) ([3]) thought that online games could improve the satisfaction of players through their interactive mechanisms. Mao (2007) ([2]) thought that the developers and operators of online game should cooperate to increase their profits and reduce their costs. China's Ministry of Culture and Ministry of Information Industry (2005) ([1]) have proposed the national game boutique project, the online game industry incubator, and the online game industry support policy to be the important parts of the network industry support policy.

The scales of online game industry in various countries are all huge and their sales keep increasing. For example, International Data Corporation (IDC, 2017) ([4]) found that the amount of game sales in China was RMB 203.61 billion in 2017 (its annual growth rate more than $23.0 \%$ ), and the number of game players was 583 million $(3.1 \%)$. The sales amounts of mobile games, client game, web games and console games were RMB 116.12 billion,
RMB 64.86 billion (31.9\%), RMB 15.6 billion and RMB 1.37 billion. Chan, et al. (2015) ([22]) predicted that the sales amount of global Massively Multiplayer Online Game (MMOG) in 2018 should be USD 35 billion, and, its sales amount in 2012 was USD 21 billion and its average game time and the monthly consumption of players was three hours in a day and USD 17. (The Industry Information Network, 2016; Choi and Kim, 2004) ([7])

According to the review of literatures, the influencing factors of consumer behavior of online game should be the cognitions of the advantages, disadvantages, quality advantages, and quality disadvantages of online game. The literatures about the cognitions on the advantages of online game are as Dong (2018) ([8]) thought that online games could improve responsiveness of its players. $\mathrm{Bu}$ (2004) ([9]) thought that online games could increase the interpersonal communication ability of their players for the unrestraint on their time and space. Zhang (2003) ([10]) thought that online games could improve the mental health of adolescent players. The literatures about the cognitions on the disadvantages of online games are as Chiu, et al. (2004) ([7]) thought that players might be addicted to online games, even leading to their learning problems (as their unconcentration on learning). Ma (2013) ([12]) thought that the game time of online game players is too much to have time allocation problems. The literatures about the cognitions on the quality advantages of online game are as Zhang (2003) ([10]) thought that the style and background music of online game are the influencing factors of its consumer's loyalty. Luo et al. (2005) ([13]) found the style of online games is a key factor of consumers' first game behavior. Zhao and Zhang

\footnotetext{
${ }^{\mathrm{a}}$ Corresponding author: huangwl@wzbc.edu.cn
} 
(2018) ([14]) thought the characters in online games would affect the quality of the game. There is no relevant literature for the cognitions on the quality disadvantages of online game now.

In the other side, this paper also discusses the impact of the individual variables of online game player on consumer behavior of online game and its influencing factors. In addition to the introduction, the second part of this paper is the literature review of consumer behavior of online game and its influencing factors, the third part is the analysis of questionnaire results, and the fourth part is the conclusion and suggestion.

\section{Literature review}

The scale and players of the online game industry in many countries are quickly expanding, especially in the mobile game industry. For example, Global Mobile Game Confederation (2015) ([15]) found the proportion of online game players who are willing to pay in Indonesia and Thailand is the highest, and the average annual spending of mobile game players in Southeast Asia is USD 174. The average age of mobile game players in Indonesia, Malaysia, the Philippines, Singapore, Thailand and Vietnam is between $21 \sim 35$ years old, and men account for $55 \%$ of them.

According to the literatures review, consumer behavior of online game should be an important research topic, but there are still few literatures discussing it and its influencing factors. This paper sorts out the existing literatures in China and finds that the literatures of online games (in the title) began in 1997, and the total number of papers reached 3,225 by October 25, 2018. The literatures of online game consumption (in the title) began in 2001, and there were only 29 papers till October 25,2018 , which research field mainly belongs to the information economy, and their content focuses on consumption behavior of online game and current situation, but less literature studied the impact of its influencing factors and individual variables of online game players. Therefore, the focus of this paper is to explore the consumer behavior of online game and its influencing factors, and then to makeup the deficiencies in the literature of online game, and also to provide advices to individuals, businesses and the government.

In this paper, the variables are defined as follows: 1 . the variables of online game consumer behavior are defined as player's monthly consumption amount and player's daily game time. As Zhiyan Consulting Co., Ltd. (2017) ([25]) found that the average annual cost of Chinese online game players is RMB 960. Game Confederation (2015) ([15]) found the proportion of players in the world who play more than 10 hours per week in mobile game is $5 \%$, and the average play time of Chinese players per day in online games is more than 30 minutes. Wei (2005) ([16]) thought that the online game consumer behavior should be the online game player's weekly consumption and $15 \%$ of players spending more than RMB 120 for online game. Wei and Chi (2004) ([17]) defined the variables of online game consumer behavior are player's weekly game time and monthly consumption amount.

2. The variables for the cognitions on the advantages of online game are defined as the growth of reaction capacity, concentration, communication ability, optimistic attitude, teamwork ability, and communication ability. For example, Gong (2018) ([18]) defines the advantages of online game are online games could increase the reaction capacity of player's living, the chatting topics with friends, consumer satisfaction and fun, the teamwork ability. ([10], [19])

3. The variables for the cognitions on the disadvantages of online game are defined as the problems of health, social anxiety, learning, game addiction, and time allocation. For example, Gong (2018) ([18]) defines the disadvantages of online game are online games would make players have the problems of vision, joint, learning performance, and the insufficient time of other activities (learning or sleeping). China Internet Network Information Center (2010) ([19]) and Zheng and Luo (2006) ([20]) define the game addiction of online game player as player would keep on playing online games and be depressed when it stop. Gao (2017) ([21]) defines the social anxiety of online game player as negative emotions such as anxiety and depression that player will reduce its motivation to interact with people because of online games.

4. The variables for the cognitions on quality advantages of online game are defined as the pleasing on the character, style, background music, plot, freedom of players' behavior, and whole design of online game. For example, Christy, et al. (2015) ([22]) and Walrave and Ponnet (2016) found the quality advantages of online game are the freely setting the character by online game player, and online game pictures which are the consumer's favorite type. Choi and Kim (2004) ([7]) and Zhang (2003) ([10]) found the quality advantages of online game are the vividness and quality about the sound and background music of the picture. Hamari (2015) ([23]) defines freedom of players' behavior as online game players have the freedom to choose to pay for online game or not. Interim Measures for Online Game Management (2010) ([24]) thought that the whole design of online games should include its background, plot, and the system of economic, trading, production, construction, social, confrontation, character, sound, effects, map, props, action, team, task, etc.

5. The variables for the cognitions on the quality disadvantages of online game are defined as high cost, low playability, and slow updates of online game. For example, China Internet Network Information Center (2010) ([19]) and Chen, et al. (2006) ([26]) found high consumption of game, the proliferation of plug-ins and bugs (such as the blurred system information of online games) would reduce players' willing to play online game.

6. The individual variables of online game player are defined as player's gender, age, occupation (student and non-student), monthly income, and the type of played game (mobile games and computer games). For example, China Internet Network Information Center (2010) ([19]) found that the proportions on individual variables of 
online game players are: male players are $1 / 3$ of the female, players at the age of 10-19 account for $42.4 \%$, students account for $40.7 \%$, and players whose monthly income is over RMB 500 account for $30.6 \%$. The China Cultural and Entertainment Industry Association (2017) ([27]) found that the number of mobile game players in 2017 was 460 million.

\section{Analysis of questionnaire results}

This paper conducted 700 online questionnaires in China from July 14 to 21,2018 . The statistical results of the respondents' individual variables were: 1 . Gender: males account for $64.30 \%$ and females account for $35.70 \%$. 2 . Age: The average age of respondents is 20.39 years old (standard deviation is 1.41). 3. Occupation: students account for $65.60 \%$ and non-students account for $34.40 \%$. 4. Monthly income: The average monthly income of respondents is RMB 1,708.57 (standard deviation was 695.94). 5. The type of played game: mobile game players account for $63.00 \%$, and computer game players account for $37.00 \%$.

The descriptive statistics about the variables of online game consumer behavior and its influencing factors are: 1 . player's monthly consumption amount is RMB 157.57 (standard deviation is 110.58), and player's daily game time is 2.90 hours (standard deviation is 1.59). 2. $2 / 3$ respondents approve that the influencing factors of online game consumer behavior are the advantages, quality advantages, and quality disadvantages of online game, but $45.70 \%$ respondents approve with the cognitions on the disadvantages of online game. As $90.60 \%$ of the respondents most approve with the growth of reaction capacity about player's cognitions on advantages of online game; $58.10 \%$ of the respondents most approve with the game addiction about player's cognitions on disadvantages of online game; $92.00 \%$ of the respondents most approve with the pleasing on the whole design of online game in the variables anout the cognitions on the quality advantages of online game and $80.30 \%$ of respondents most approve with high game cost of online game in the variables of the cognitions on the quality disadvantages of online game.

The ANOVA results between online game consumer behavior and its influencing factors are shown in Table 1. From Table 1, the significant factors of consumer behavior of online game are the cognitions on the advantages, disadvantages, quality advantages, and quality disadvantages of online game.

Table 1. The ANOVA results between online game consumer behavior and its influencing factors.

\begin{tabular}{|c|c|c|c|}
\hline \multicolumn{2}{|c|}{} & \multicolumn{2}{|c|}{$\begin{array}{c}\text { Consumer behavior of } \\
\text { online game }\end{array}$} \\
\cline { 3 - 4 } & Consumption & $\begin{array}{c}\text { Game } \\
\text { time }\end{array}$ \\
\hline \multirow{2}{*}{$\begin{array}{c}\text { Influencing } \\
\text { factors }\end{array}$} & $\begin{array}{c}\text { Cognitions on the } \\
\text { advantages of } \\
\text { online game }\end{array}$ & $15.54^{* * *}$ & $4.02^{* *}$ \\
\cline { 2 - 4 } & $\begin{array}{c}\text { Cognitions on the } \\
\text { disadvantages of }\end{array}$ & $34.26^{* * *}$ & $22.67^{* * *}$ \\
\hline
\end{tabular}

\begin{tabular}{|c|c|c|c|}
\hline & online game & & $11.52 * * *$ \\
\cline { 2 - 4 } & $\begin{array}{c}\text { Cognitions on the } \\
\text { quality advantages } \\
\text { of online game }\end{array}$ & $6.10 * * *$ & $53.51 * * *$ \\
\cline { 2 - 4 } & $\begin{array}{c}\text { Cognitions on the } \\
\text { quality } \\
\text { disadvantages of } \\
\text { online game }\end{array}$ & $19.70^{* * *}$ & \\
\hline$* \mathrm{p}<0.05, * * \mathrm{p}<0.01, * * * \mathrm{p}<0.001$ &
\end{tabular}

To further understand the results of the questionnaire, this paper explores the impact of gender, age, occupation, monthly income, and played game type of player on online game consumer behavior and its influencing factors (see Table 2). From Table 2, player's gender and monthly income would have significant impacts on the consumption of online game. As male player's monthly consumption is RMB 43.51 more than that of female. Age and career have a significant impact on consumer behavior of online game. The older is the player, the more is its consumption of online game, and the younger is the player, the longer is its game time. Non-students' monthly consumption of online game is RMB 46.65 more than that of students. And students' daily game time is 1.67 hours significantly more than that of non-students. Player's played game type has no significant impact on consumer behavior of online game.

Player's gender, age, and monthly income have significant impacts on the influencing factors of online game consumer behavior. For example, male player's cognitions on the advantages and quality disadvantage of online game are significantly greater than that of female, while female player's cognitions on the disadvantages of the game is significantly greater than that of male. And younger players have greater cognitions on the advantages and quality disadvantages of online game. As well as players who have lower monthly income have greater cognitions on quality advantages of online game. Player's occupation and played game type have significant impacts on the cognitions of advantages and quality disadvantages of online game, and player's played game type has a significant impact on the cognitions of advantages of the game. For example, student players' cognitions on the advantages and quality disadvantages of online game are significantly higher than that of nonstudents. The cognitions on quality disadvantages of mobile games players are significantly greater than those of computer games, while the cognitions of advantages and quality advantages of computer games players are greater than those of mobile games players.

According to the above discussion results, this paper suggests: 1 . More than 1/4 of players would spend more than RMB 200 on online games per month, and this consumption accounts for about $1 / 8$ of their monthly income, this proves that most players are willing and able to pay for online games. From the perspective of government and enterprises, the online game industry should be actively developed, but the government should limit the online game consumption of group with no income. For example, Notice on Implementing "Chinese National Online Game Publishing Project (2004) ([28]) actively promotes outstanding ethnic original online games. The proportion of players whose game time is 
more than 3 hours in a day accounts for $1 / 2$, and $2 / 3$ of that is minors. Therefore, the government and enterprises should strengthen the regulations and time control software for the game time of minors. For example, Development Standards for Online Game Anti-addiction (2007) ([29]) regulates the health game time for minors is within 3 hours. And more and more online games adopt ID authentication mechanism to regulate the different game time of players with different ages.

2. The influencing factors of online game consumer behavior have the highest approve degree with the cognitions on advantages and quality advantages of online game, so the enterprises could strengthen the marketing strategies of the above two aspects. However, most respondents approve with the cognitions on the quality disadvantages of online game, so companies still need to actively improve the quality of the game. Although respondents' approve degree with the cognitions on the disadvantages of online game is quite low, many game addiction accidents continue to occur. Therefore, the government should monitor online games with pornographic and violent content, and set game content specifications for the groups in different age.

Table 2. Independent sample T-test of player's individual variables (gender, age, occupation, monthly income, and played game type) on consumer behavior of online game and its influencing factors.

\begin{tabular}{|c|c|c|c|c|c|c|}
\hline & Gender & Age & Occupation & Monthly income & Played game type \\
\hline & & $\mathrm{F}(\mathrm{T})$ & $\mathrm{F}$ & $\mathrm{F}(\mathrm{T})$ & $\mathrm{F}$ & $\mathrm{F}(\mathrm{T})$ \\
\hline \multirow{2}{*}{$\begin{array}{l}\text { Consumer } \\
\text { behavior of } \\
\text { online game }\end{array}$} & Consumption & $\begin{array}{c}21.02 * * * \\
(-5.18 * * *)\end{array}$ & $4.37 *$ & $\begin{array}{c}4.22 * \\
(-5.63 * * *)\end{array}$ & $\begin{array}{c}21.02 * * * \\
(-5.18 * * *)\end{array}$ & $\begin{array}{c}0.24 \\
(-0.74) \\
\end{array}$ \\
\hline & Game time & $\begin{array}{c}18.76^{* * *} \\
(-0.43)\end{array}$ & $\begin{array}{c}139.29 * * \\
*\end{array}$ & $\begin{array}{c}9.89 * \\
(15.41 * * *)\end{array}$ & $\begin{array}{c}18.76^{* * * *} \\
(-0.43)\end{array}$ & $\begin{array}{c}6.01 * \\
(-0.14)\end{array}$ \\
\hline \multirow{4}{*}{$\begin{array}{l}\text { Its Influencing } \\
\text { factors }\end{array}$} & $\begin{array}{l}\text { Cognitions on the } \\
\text { advantages of online } \\
\text { game } \\
\end{array}$ & $\begin{array}{c}7.20 * * \\
(-4.28 * * *)\end{array}$ & $3.04 *$ & $\begin{array}{c}0.32 \\
(0.49)\end{array}$ & $\begin{array}{c}7.20 * * \\
(-4.28 * * *)\end{array}$ & $\begin{array}{l}7.59 * * \\
(-2.32 *)\end{array}$ \\
\hline & $\begin{array}{c}\text { Cognitions on the } \\
\text { disadvantages of online } \\
\text { game }\end{array}$ & $\begin{array}{c}0.89 \\
(5.72 * * *)\end{array}$ & $6.37 *$ & $\begin{array}{c}2.24 \\
(0.16)\end{array}$ & $\begin{array}{c}0.89 \\
(5.72 * * *)\end{array}$ & $\begin{array}{c}2.24 \\
(0.16)\end{array}$ \\
\hline & $\begin{array}{c}\text { Cognitions on the quality } \\
\text { advantages of online } \\
\text { game }\end{array}$ & $\begin{array}{c}18.30 * * * \\
(-3.89 * * *)\end{array}$ & $16.00 * * *$ & $\begin{array}{l}32.43 * * * \\
(4.34 * * *)\end{array}$ & $\begin{array}{c}18.30 * * * \\
(-3.89 * * *)\end{array}$ & $\begin{array}{c}8.07 * * \\
(5.41 * * *)\end{array}$ \\
\hline & $\begin{array}{c}\text { Cognitions on the quality } \\
\text { disadvantages of online } \\
\text { game }\end{array}$ & $\begin{array}{c}1.75 \\
(6.37 * * *)\end{array}$ & $61.21 * * *$ & $\begin{array}{l}140.52 * * * \\
(8.98 * * *)\end{array}$ & $\begin{array}{c}1.75 \\
(6.37 * * *)\end{array}$ & $18.91 * * *(-3.82 * * *)$ \\
\hline
\end{tabular}

$* \mathrm{p}<0.05, * * \mathrm{p}<0.01, * * * \mathrm{p}<0.001$

3. According to the statistics of the nine influencing factors of the cognitions on the quality advantages and quality disadvantages of online game, the game's whole design, style and character have the highest approval degrees, and the approve degree of other six factors are more than $80 \%$. Therefore, the designer of the online game should consider the nine influencing factors mentioned in this paper.

4. According to the significant influence of player's individual variables on online game consumer behavior and its influencing factors, companies could formulate differentiated marketing strategies based on player's gender, age, occupation, monthly income and played game types. Such as the strengthening the social function and the pleasing of the painting for female players in online games.

\section{Conclusion and suggestion}

Nowadays, the online game industry in more and more continues is an important industry for development, so the consumer behavior of online game and its influencing factors should be an important topic for enterprises, governments and scholars to study, and it is the research target of this paper. And this paper also analyzes the impact of player's gender, age, occupation, monthly income and played game type.
According to the literature review and the results of the questionnaire, it is found that player's monthly consumption exceeds RMB 150, and player's daily game time is about 3 hours. And player's the advantages, quality advantages, quality disadvantages, and disadvantages should be significant influencing factors of consumer behavior of online game, and its influencing degree is decreasing. Player's gender, age, occupation, and monthly income should be different with the consumer behavior of online game and its influencing factors and the type of played game should be different with its influencing factors. Based on the above discussion, this paper suggests that the government should actively promote the development of online games, including the research and development policies of online game derivative products, the export assistance and preferential policies of domestic online game. In the other side, the government should actively guide the game time and consumption of adolescents in online game. It is recommended that enterprises should carry out differentiated marketing strategies for different group with player's individual variables. The research and development strategy of online game should be focus on its whole style, character design, and social functions, and set the age admission mechanism for identity authentication. For example, Opinions of the Ministry of Culture and the Ministry of Information Industry on the Development and Management of Online Games (2005) 
([30]) thought that online games industry should actively develop their peripheral, such as journals, audio-visual products, toy, stationery, food, clothing, facilities, animation and shows, etc.

The future research directions of this paper should include the impacts of the design system and satisfaction evaluation system in online game on online game consumer behavior and its influencing factors. For example, Yang and $\mathrm{Hu}$ (2007) ([31]) found that the online game design system and satisfaction evaluation system would establish consumer demand.

\section{References}

1. China's Ministry of Culture and Ministry of Information Industry, Several opinions on the development and management of online games (2005)

2. Mao, X., Contemporary Finance \& Economics, 102 (2007)

3. Zhang, J., Technology development, 119 (2015)

4. International Data Corporation, 2017 China Game Industry Report (2017)

5. Chan, T., Cheung, C., Lee, Z., International Journal of Business and Information, 161 (2014)

6. Industry Information Network, Research Report on the Operational Situation and Development Trend of China's Online Game Market in 2016-2022 (2016)

7. Choi, D., Kim, J., CYBERPSYCHOLOGY \& BEHAVIOR, 11 (2004)
8. $\quad$ Dong, K., PC Fan, 239 (2018)

9. Bu, P., Youth, 122-125 (2014)

10. Zhang, Y., Network Era, 92-94 (2003)

11. Chiu S.I., Lee J.Z., Huang D.H., Cyber Psychology \& Behavior, 7(5), 571-581

12. Ma, B., Education Forum, 184 (2013)

13. Luo, S., Wang, Z., Fang, W., Electronic Commerce Studies, 3(3), 289-308 (2005)

14. Zhao, X., Zhang, W., Visual Design, 67 (2018)

15. Global Mobile Game Confederation, 2015 Global Mobile Game Industry White Book, 3-19 (2018)

16. Wei, Y., Statistical Observation, 78 (2005)

17. Wei, Y., Chi, B., Journal of Shanxi Institute of Economic Management, 17-79 (2004)

18. Gong, J., Mental Health Education in Primary and Secondary Schools, 8-13 (2018)

19. China Internet Network Information Center, 2010 China Online Game Player Research Report (2010)

20. Zheng, Z., Luo, R., Journal of Tianjin Institute of Education, 32-34 (2006)

21. Gao, C., Journal of Liaoning Normal University, 10$41(2017)$

22. Christy M.K., Chueng A,. Shen, X., Zach W.Y., Lee A., Tommy K.H., Chan, Electronic Commerce Research and Applications, 241-250 (2015)

23. Juho, Hamari, International Journal of Information Management, 299-308 (2015)

24. Interim Measures for Online Game Management (2010) 